\title{
Long-Term Land Deformation Monitoring Using Quasi-Persistent Scatterer (Q-PS) Technique Observed by Sentinel-1A: Case Study Kelok Sembilan
}

\author{
${\text { Pakhrur Razi1,2, Josaphat Tetuko Sri Sumantyo², Daniele Perissin }{ }^{3} \text {, Hiroaki Kuze }}^{2}$ \\ ${ }^{1}$ Physics Department, Universitas Negeri Padang, Sumatra, Indonesia \\ ${ }^{2}$ Center for Environmental Remote Sensing, Chiba University, Chiba, Japan \\ ${ }^{3}$ Lyle School of Civil Engineering, Purdue University, West Lafayette, IN, USA \\ Email: fhrrazi@fmipa.unp.ac.id, fhrrazi@chiba-u.jp
}

How to cite this paper: Razi, P., Sumantyo, J.T.S., Perissin, D. and Kuze, H. (2018) Long-Term Land Deformation Monitoring Using Quasi-Persistent Scatterer (Q-PS) Technique Observed by Sentinel-1A: Case Study Kelok Sembilan. Advances in Remote Sensing, 7, 277-289.

https://doi.org/10.4236/ars.2018.74019

Received: September 26, 2018

Accepted: December 11, 2018

Published: December 14, 2018

Copyright (ㅇ 2018 by authors and Scientific Research Publishing Inc. This work is licensed under the Creative Commons Attribution International License (CC BY 4.0).

http://creativecommons.org/licenses/by/4.0/

c) (†) Open Access

\begin{abstract}
Located on the mountainous area, Kelok Sembilan flyover area in West Sumatra, Indonesia has a long history of land deformation, therefore monitoring and analyzing as continuously is a necessity to minimize the impact. Notably, in the rainy season, the land deformation occurs along this area. The zone is crucial as the center of transportation connection in the middle of Sumatra. Quasi-Persistent Scatterer (Q-PS) Interferometry technique was applied for extracting information of land deformation on the field from time to time. Not only does the method have high performance for detecting land deformation but also improve the number of PS point, especially in a non-urban area. This research supported by 90 scenes of Sentinel-1A (C-band) taken from October 2014 to November 2017 for ascending and descending orbit with VV and VH polarization in $5 \times 20 \mathrm{~m}$ (range $\times$ azimuth) resolution. Both satellite orbits detected two critical locations of land deformation namely as zone A and Zone B, which located in positive steep slope where there is more than $500 \mathrm{~mm}$ movement in the Line of Sight (LOS) during acquisition time. Deformations in the vertical and horizontal direction for both zone, are $778.9 \mathrm{~mm}, 795.7 \mathrm{~mm}$ and $730.5 \mathrm{~mm}, 751.7 \mathrm{~mm}$, respectively. Finally, the results were confirmed by ground truth data using Unmanned Aerial Vehicle (UAV) observation.
\end{abstract}

\section{Keywords}

Interferometry, Synthetic Aperture Radar, Land Deformation, Q-PS Technique, Kelok Sembilan 


\section{Introduction}

Kelok Sembilan flyover (Figure 3) located in "V" shape terrain steep slope and high rainfall intensity area [1], with the latitude of $0^{\circ} 4^{\prime} 13.30^{\prime \prime} \mathrm{S}$ and longitude of $100^{\circ} 41^{\prime} 53.56^{\prime \prime} \mathrm{E}$ West Sumatra, Indonesia are necessary to be monitored and analyzed, since the Indonesia National Agency for Disaster Management (BNPB) has categorized the areas into middle and high land movement [2]. Almost every year landslide occurs around the zone. On March 3, 2017, there was large-scale landslide incident in West Sumatra-Riau connection, where 64 locations of landslide occurred, two of which are on Kelok Sembilan flyover. Monitoring is required to obtain the scientific information about the characteristic of land movement and its critical locations from time to time. Experimental data can be used to analyze the impact and prevent the probability of the hazard coming in future. Also, Kelok Sembilan flyover located near the active Kelok Sembilan-Solok Bio-Bio Fault that contributed to triggering the land movement.

Monitoring land deformation in time series is severe to be carried out by the traditional method such as using Global Positioning System (GPS) because this method not only needs to install and fix some of the instruments on the site but also take more time and spend high cost. However, Persistent Scatterer Interferometric (PSI) Synthetic Aperture Radar (SAR) technique has offered a solution. Moreover, the method has proven valid and reliable for measuring multitemporal land deformation on the earth surface by investigating point-like radar target during acquisition time [3]. Furthermore, the technique can observe a wide range of deformation area in both subsidence and uplift [4]. Some applications that applied PSI-SAR technique to earth observation are such as seismic fault [5], coastal sedimentation monitoring [6], volcanos [7], landslide [8] with accuracy $1 \mathrm{~m}$ for height and $1 \mathrm{~mm}$ in displacement [9]. However, when PSI-SAR technique applied in the non-urban area, the number of permanent scatterers (PS) target is low [10]. To overcome the PS problem the distribution scatterer on target should be considered to extract, then the number of PS point distribution on spatial can be improved. Additionally, there is some condition propelling to less detection of the PS target because of the low coherence, namely 1) local steep slope, 2) vegetation, 3) time repeat pass of the satellite $\left.B_{t}, 4\right)$ normal baseline $\left.B_{n}, 5\right)$ poor co-registration [11]. In Kelok Sembilan flyover area, two of five conditions above occupied ( 1 and 2 ) and others (3, 4, and 5) depend on interferometry processing technique used, and satellite data selected. Therefore, the technique used is known as Quasi-Permanent Scatterer (Q-PS) Interferometry SAR technique. Processing SAR data using PSI and Q-PS technique is relatively equal. Nevertheless, three points have adjustment namely [10]: 1) The images in the dataset is not correlating with one master image, 2) Displacement and height of target exploited from partial coherent target subset of the interferogram, 3) Spatial filtering is applied to extend the signal-to-noise ratio.

The availability of interferometry SAR data Sentinel-1A, provided by European Space Agency (ESA) has been used to extract the information about Kelok 
Sembilan flyover area in time series. This data was selected because Sentinel-1A (C-band) SAR images have a small perpendicular baseline $B_{n}$ (about $200 \mathrm{~m}$ ) and temporal baseline $B_{t}$ (12 days) as well, then geometric and temporal decorrelation was not issued in SAR processing. Furthermore, it can improve the accuracy of measurement, but by applying short wavelength (C-band) on vegetation area, it will decline the density PS point [12] compared with a previous investigation using long wavelength (L-band) [8].

Recently, the application of the PSI technique for monitoring land deformation over the area using ALOS PALSAR (L-band) with linear cross-polarization HV (Horizontal transmit, Vertical receive) was published [8]. However, the observation is limited for ascending orbit direction. In this research, besides continuing the inspection on the area, an investigation of land deformation uses short wavelength (C-band) for both sides of the field with " $V$ " contour shape from ascending and descending orbit.

The objectives of the research are mapping and monitoring land deformation in "V" shape area using Q-PS interferometry SAR technique with short radar wavelength (C-band) for ascending and descending orbit. The result from Q-PS analysis is verified by small Unmanned Aerial Vehicle (UAV) observation. Consequently, the map will be useful for local government as scientific information of time series land deformation on the area and plan to prevent the impact.

\section{Study Area and Satellite Dataset}

Kelok Sembilan area located in Lima Puluh Kota district and has been the main road playing an essential role in supporting economic and transportation in the center of Sumatera Island. The area recorded as a high land movement [13] due to topography and geology condition. The ranges of topographical in both positive and negative slope are between 500 - 750 and 340 - 700 respectively [8]. Based on geology survey, at least two shapes of fault around Kelok Sembilan area are a namely normal fault and strike-slip fault. Also, the rock structure is shared-joint constructed of metamorphic rock and sedimentary rock [8]. The complexity of the geology condition in the area leads to the high probability of landslide occurrence. In three recent years from 2015-2017, 110 locations of a landslide are along the area connection between West Sumatra and Riau Province [14]. Studying and monitoring a characteristic of land deformation in the area is a necessity as scientific information for preventing and early warning for the transportation and resident.

For monitoring land deformation at the Kelok Sembilan area, 36 scenes ascending and 54 scenes descending orbit of Sentinel 1A C-band SAR satellite was extracted. The time acquisition of data was taken from October 2014 to 7 December 2017. Both orbits of the spacecraft were selected for obtaining information in different view of Line-of-Sight (LOS) and identifying the consistency of land deformation zone detection by satellite. The track orbit of satellite Sentinel-1A is shown in Figure 1. 


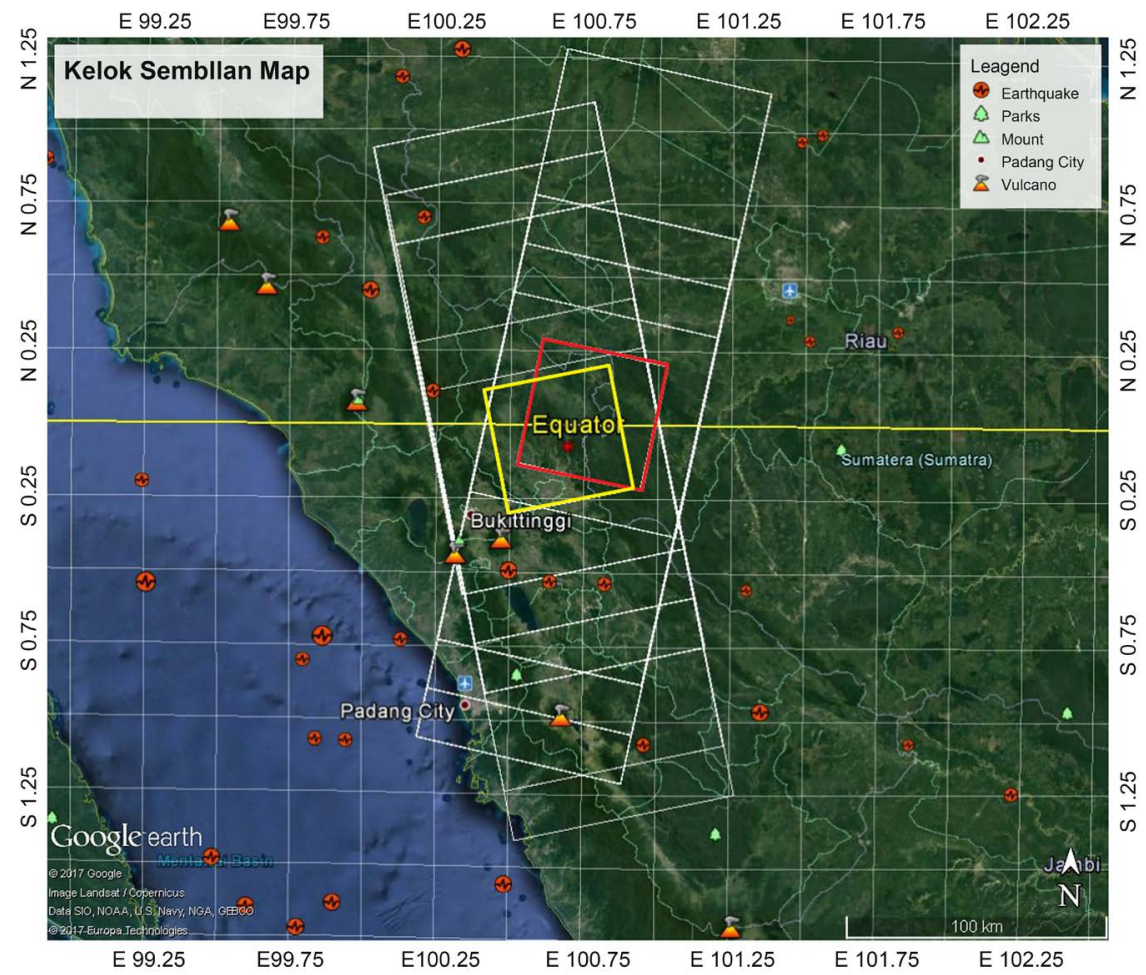

Figure 1. Sentinel-1A satellite with ascending and descending orbit. Investigation area for both ascending and descending orbit is marked by yellow square and red square respectively. Kelok Sembilan located near the equator line (yellow line) at a latitude of $00^{\circ} 4^{\prime} 13.30^{\prime \prime S}$ and longitude of $1000^{\circ} 41^{\prime} 53.56^{\prime \prime E}$.

The polarization of SAR data is linear co-polarization VV (vertical transmit and vertical receive), and cross-polarization $\mathrm{VH}$ (vertical transmit and horizontal receive) with wavelength is $5.44 \mathrm{~cm}$ (C-band). The data is provided by European Space Agency (ESA) with Interferometric Wide (IW) swath acquisition mode, in Single Look Complex (SLC) format. The product contains phase and amplitude information, geo-reference, orbit and attitude, and slant-range geometry [15]. The incidence angle $\theta_{i}$ of radar to target range for ascending and descending orbit is 33.94 degree and 43.89 degrees respectively. IW SLC format contains one image per sub-swath and polarization with $2.7 \mathrm{~m} \times 22.5 \mathrm{~m}$ (IW1) and $3.5 \times 22.6$ (IW3) spatial resolution for ascending and descending orbit respectively. Furthermore, Sentinel-1A satellite has high the critical baseline approximately until $15,882 \mathrm{~m}$. The orbit height is $693 \mathrm{~km}$ with an inclination angle 98.180 and repeats cycle orbit in 12 days [16]. The dataset of Sentinel-1A is shown in Table 1.

Sentinel-1A satellite in both ascending and descending orbit has a small normal baseline $B_{n}$ and short temporal baseline $B_{t}$. The maximum normal baseline of the scenes reached $200 \mathrm{~m}$. The lower normal baseline will reduce the geometrical decorrelation [17] and the short repeat cycle orbit (12 days) [15] decreases the temporal decorrelation which then improves the coherence value.

Figure 2 shows the topography of West Sumatra based on Shuttle Radar 
Table 1. Sentinel-1A with ascending and descending orbit dataset: part 91 frame 592 (descending), path 69 frames 1181 (ascending).

\begin{tabular}{ccccccc}
\hline No & Orbit & \multicolumn{2}{c}{ The number Beam swath } & Acquisition time & Polarization & Off-nadir angle \\
\hline 1 & Ascending & 36 & IW1 & $10 / 2014-03 / 2017$ & VV + VH & $26.00^{\circ}-32.48^{\circ}$ \\
2 & Descending & 54 & IW3 & $10 / 2014-11 / 2017$ & VV + VH & $35.35^{\circ}-40.40^{\circ}$ \\
\hline
\end{tabular}

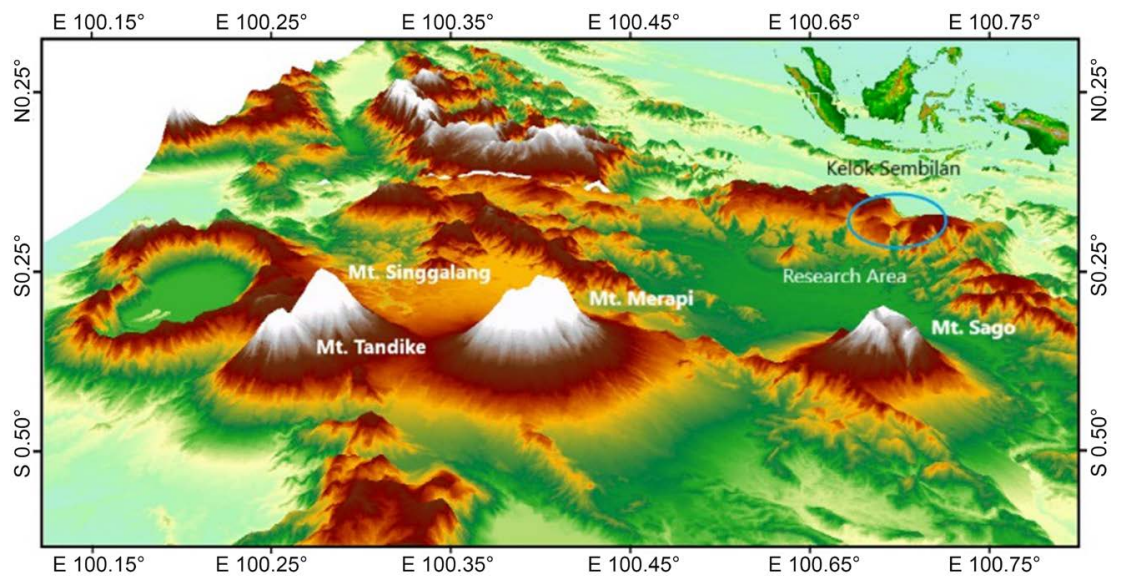

Figure 2. The topography of West Sumatra based on Shuttle Radar Topography Mission (SRTM) Digital Elevation Model (DEM) with $30 \mathrm{~m}$ resolution.

Topography Mission (SRTM) Digital Elevation Model (DEM) which is following the topography of Sumatra island. The area is mountainous and surrounded by some volcanos. In the middle of the island is spread active fault namely the Sumatra fault splitting the Sumatra east and west part from Lampung province to Aceh province. Consequences of the topography lead to arising many small faults in West Sumatra area.

In Kelok Sembilan case there are two active faults around, Kelok Sembilan-Solok Bio-Bio fault and Koto Alam fault. UAV shown in Figure 3 took the view of Kelok Sembilan area in 3D. The construction of Kelok Sembilan bridge finished in 2013, as a solution to overcome the transportation issue.

\section{Methodology}

\section{Quasi-Persistent Scatterer (Q-PS) Interferometry Technique}

Quasi-Persistent Scatterer (Q-PS) Interferometry Technique is more advanced compared to classical PSI technique that allows extracting the information from partially coherence targets $\gamma$. The basic idea of this technique is to improve the spatial distribution of measure points [10]. This technique is not only qualified in an urban area but also in the vegetated area, which can improve the spatial density of PSC [18]. Kelok Sembilan is a vegetated area with high topography, then the number of PS target is low as observed by C-band than L-band, this because of the number of PS correlated with the radar wavelength $\lambda$ and spatial resolution. To doing so, the Minimum Spanning Tree (MST) image graph 


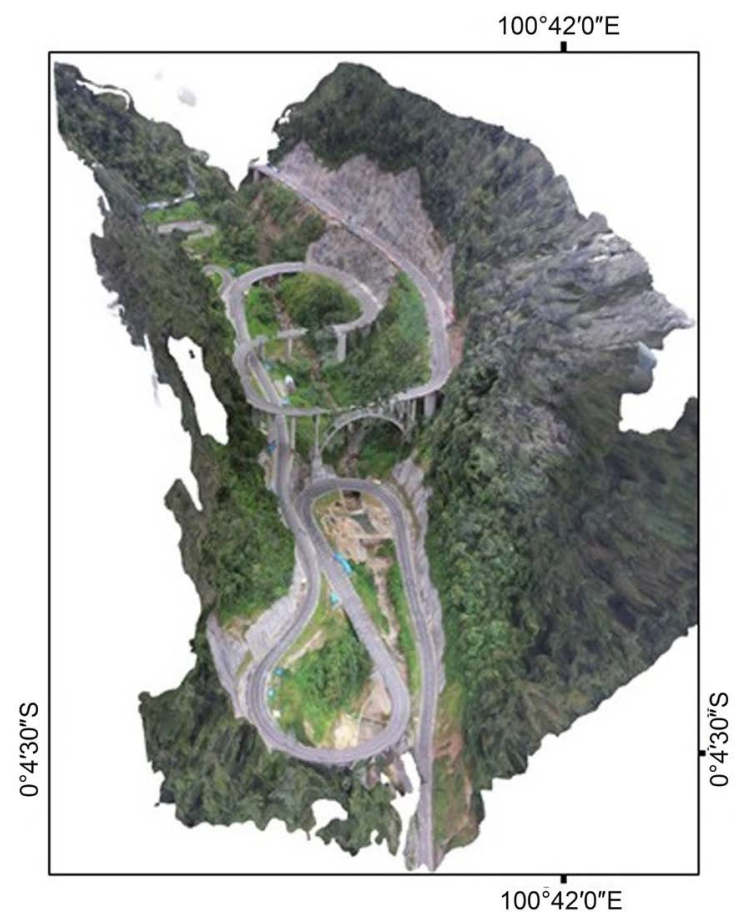

Figure 3. 3D orthophoto topography of the research area in Kelok Sembilan, Lima Puluh Kota district, West Sumatra, Indonesia, taken on September 20, 2016.

configuration with coherence as weight was applied to maximize the coherence of target $\gamma$. Three components of the image graph are considered to improve the coherence target namely: firstly, the connectivity of the image, this needed to unwrap the phase time series, secondly, the number of the link and thirdly, the weight to each link to quantify its goodness [10]. The minimum number of image links for $\mathrm{N}$ image available is $\mathrm{N} / 2$ and maximum is $\mathrm{N}(\mathrm{N}-1) / 2$ [10]. Q-PS technique with MST image graph configuration is shown in Figure 4.

In Interferometry SAR, the interferometric phase depends on geometric acquisition, topography, displacement, atmospheric effect and noise [19]. In Mathematics, the interferometric phase component follows the following equation [20] [21].

$$
\Delta \varphi_{m, s}(T)=\Delta \varphi_{m, s}^{\mathrm{flat}}(T)+\Delta \varphi_{m, s}^{\mathrm{Topo}}(T)+\Delta \varphi_{m, s}^{\mathrm{disp}}(T)+\Delta \varphi_{m, s}^{\mathrm{atm}}(T)+\Delta \varphi_{m, s}^{\mathrm{noise}}(T)
$$

Index $m$ is a master scene, and index $s$ is slave scenes of the satellite dataset. Flat phase $\Delta \varphi_{m, s}^{\text {flat }}$ component of target $T$ can be estimated and removed (flattening) from orbital satellite data. Topography phase $\Delta \varphi_{m, s}^{\text {Topo }}$ is a component corresponds to the inaccuracy of reference DEM which remain the residual height $\Delta \varphi_{m, s}^{\text {height }}$. The phase of displacement $\Delta \varphi_{m, s}^{\text {disp }}$ is the component of target $T$ that respects to reference point. Both of them can write as [21]:

$$
\begin{aligned}
\Delta \varphi_{m, s}^{\text {height }}(T) & =\frac{4 \pi}{\lambda} \frac{B_{n}}{R_{m}} \frac{\Delta h(T)}{\sin \theta} \\
\Delta \varphi_{m, s}^{\text {disp }}(T) & =\frac{4 \pi}{\lambda} B_{t} \Delta v(T)
\end{aligned}
$$




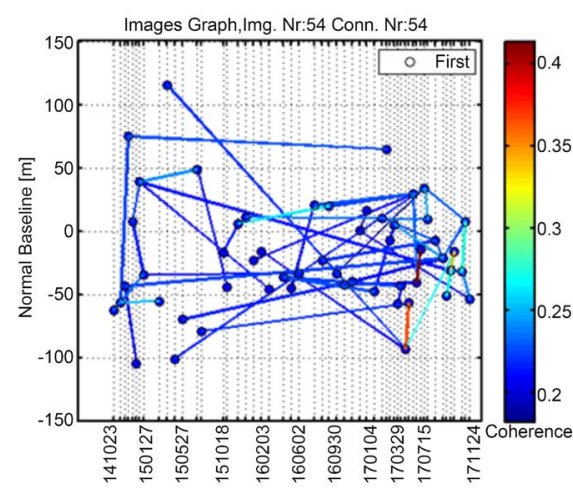

(a)

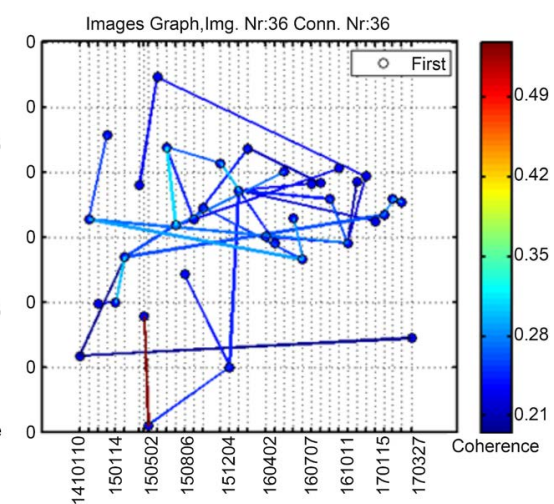

(b)

Figure 4. MST image graph configuration for Sentinel 1A SAR satellite in Q-PS technique. (a) Ascending orbit with 36 total number of SAR images; (b) Descending orbit supported by 54 SAR images. The vertical axis is the normal baseline $B_{n}$ in meter units, and the horizontal axis is the temporal baseline $B_{t}$ (YYMMDD).

where $\lambda$ is wavelength, $B_{n}$ is normal baseline, $R_{m}$ is slant range satellite to reference point, $\Delta h$ is the height of the target, $B_{t}$ is the temporal baseline, and $\Delta v$ is average the movement of the target $T$. The atmospheric phase $\Delta \varphi_{m, s}^{\text {atm }}$ component estimated through graph inversion algorithms [22]. Furthermore, the noise phase component $\Delta \varphi_{m, s}^{\text {noise }}$ can be removed by applying some filtering and multi-looking.

Estimating the atmospheric phase at the pixel position in all interferogram is carried out by selecting the Persistent Scatterer Candidate (PSC) based on amplitude stability index (ASI), (ASI $\left.=1-D_{a}\right)$. The amplitude dispersion $D_{a}$ [20].

$$
D_{a}=\frac{\sigma_{a}}{m_{a}}
$$

where $\sigma_{a}$ is the temporal standard deviation of the amplitude value and $m_{a}$ is the temporal means of the amplitude value. The points are selected as PSC if the amplitude dispersion $D_{a}<0.25$ for urban area [3], and $D_{a}<0.4$ for vegetation area [23] or $D_{a}<0.4$ [20] with minimum PSC density $3 \mathrm{PCS} / \mathrm{km}^{2}$ [24].

To analyze all target, each the close point of PSC selection is connected to each other referring to the single reference point. The networking followed the Delaunay triangulation algorithm [25]. This approach creates more redundancy network to improve the ability for detecting the phase ambiguity errors and the robustness of the network. After estimation, the atmospheric phase can be removed and then Persistent Scatterer in time series obtained. The workflow for QPS processing is shown in Figure 5.

\section{Result and Discussion}

Investigation of land deformation in this research is based on the Quasi-Persistent Scatterer Interferometry SAR technique. The data processing is provided by ESA 


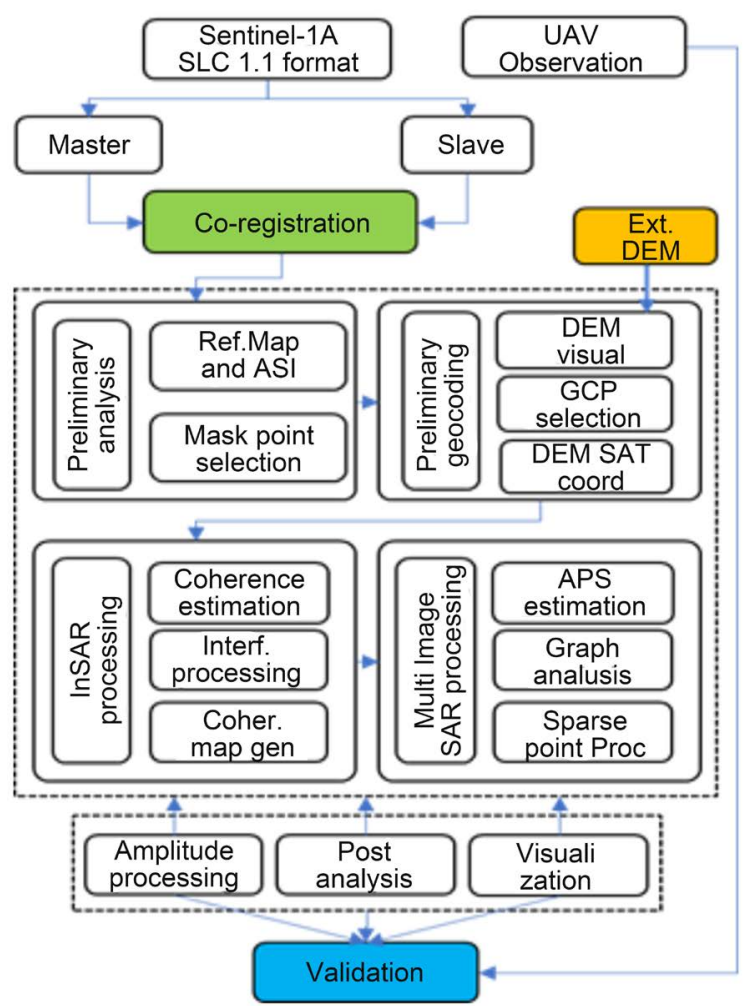

Figure 5. QPS Interferometry SAR processing workflow.

Sentinel 1A satellite in ascending and descending orbit. The time acquisition was taken from October 2014 to March 2017 and October 2014 to November 2017, respectively. For preliminary geocoding and removing the topographic phase component, Shuttle Radar Topography Mission (SRTM) Digital Elevation Model with one arcsec resolution used. Furthermore, Amplitude Stability Index (ASI) was applied to estimate the preliminary parameter and Atmospheric Phase Scene (APS) through Permanent Scatterer Candidate (PSC) network with threshold 0.6. For both data ascending and descending orbit with area range and azimuth $220 \times 600$ pixel is 2136 PSC and $220 \times 900$ pixel is 3320 PSC was selected, respectively.

Figure 6 presented the permanent scatterer candidate distribution at Kelok Sembilan area where for ascending orbit, PSC distribution is slightly smooth along the field, although some zone is sparse. Otherwise, for descending orbit, PCS distribution at range $300-400$ pixel is not homogeneous, this because at the track there is a shadowing. Based on RSTM DEM, the slope range on the field is $30^{\circ}-75^{\circ}$ [8] while the off-nadir angle of Sentinel-1A on the part (IW3) is typically in the range $35.35^{\circ}-40.40^{\circ}$ [16] then some area cannot be penetrated by satellite signal.

In repeat-pass SAR interferometry, different time acquisition will create the different atmospheric condition. Therefore, the atmospheric disturbance is a necessity for estimating and removing to improve the precision of displacement and height estimation measurement. To doing so, PSC selection is connected 

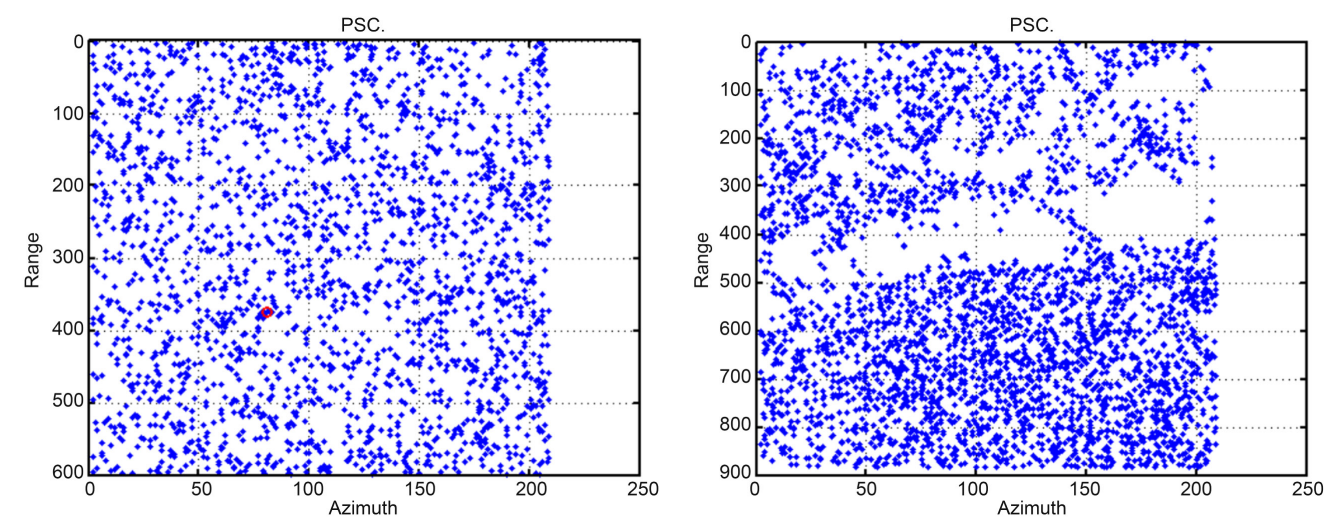

Figure 6. Permanent Scatterer Candidate selection for ascending and descending orbit of Sentinel-1A SAR satellite at Kelok Sembilan area. The total number of PCS for both orbits is 2136 and 3320, respectively.

based on the Delaunay triangular principle with a single reference point in Atmospheric Phase Screen (APS) processing. After atmospheric estimation and remover, PS obtained.

The main component result of Q-PS processing is the velocity and height of PS point which represented the parameter of land deformation. The ascending and descending orbit of land deformation velocity around Kelok Sembilan area shown in Figure 7(a) and Figure 7(c) and height in Figure 7(b) and Figure 7(d), respectively. In both track orbit, the majority PS points analyzed are located on a steep slope and high elevation (Figure $7(\mathrm{~b})$ ). In the valley area for ascending observation, the density of PS point is low because the platform is moving parallelly with terrain slope and the topography slope over the area is more than the off-nadir angle $\theta\left(26.00^{\circ}-32.48^{\circ}\right)$ which blocked the satellite signal and penetrated to the valley. However, slightly different for descending orbit, the PS density higher because the satellite slightly crosses topography then some signals reach into some areas in the valley.

For the area, $1.5 \times 0.97 \mathrm{~km}^{2}$ as observed by ascending and descending orbit and covered by vegetation, 474 PS and 684 PS have been selected with temporal coherence $\gamma>0.8$ respectively. It is a high-quality value for estimating the height and velocity. The maximum velocity in this observation is more than 120 $\mathrm{mm}$ /year and $180 \mathrm{~mm} /$ year (red color) during acquisition time for both orbits, respectively. Figure 7(b) and Figure 7(d) depicted the terrain height of PS point. The maximum and minimum height of PS point is $980 \mathrm{~m}$ (red color) and $700 \mathrm{~m}$ (blue color), and $1200 \mathrm{~m}$ and $600 \mathrm{~m}$ above sea level for ascending and descending orbit, respectively.

Figure 8 shows PS point which represented land deformation on Kelok Sembilan area obtained from Q-PS processing, that geocoded into google earth optical layer. The PS point extracted from ascending and descending observation orbit, with VV (vertical transmit and vertical receive) and VH (vertical transmit and horizontal receive). The acquisition time was taken from October 2014 to March 2017 and October 2014 to November 2017 for both orbit directions with 

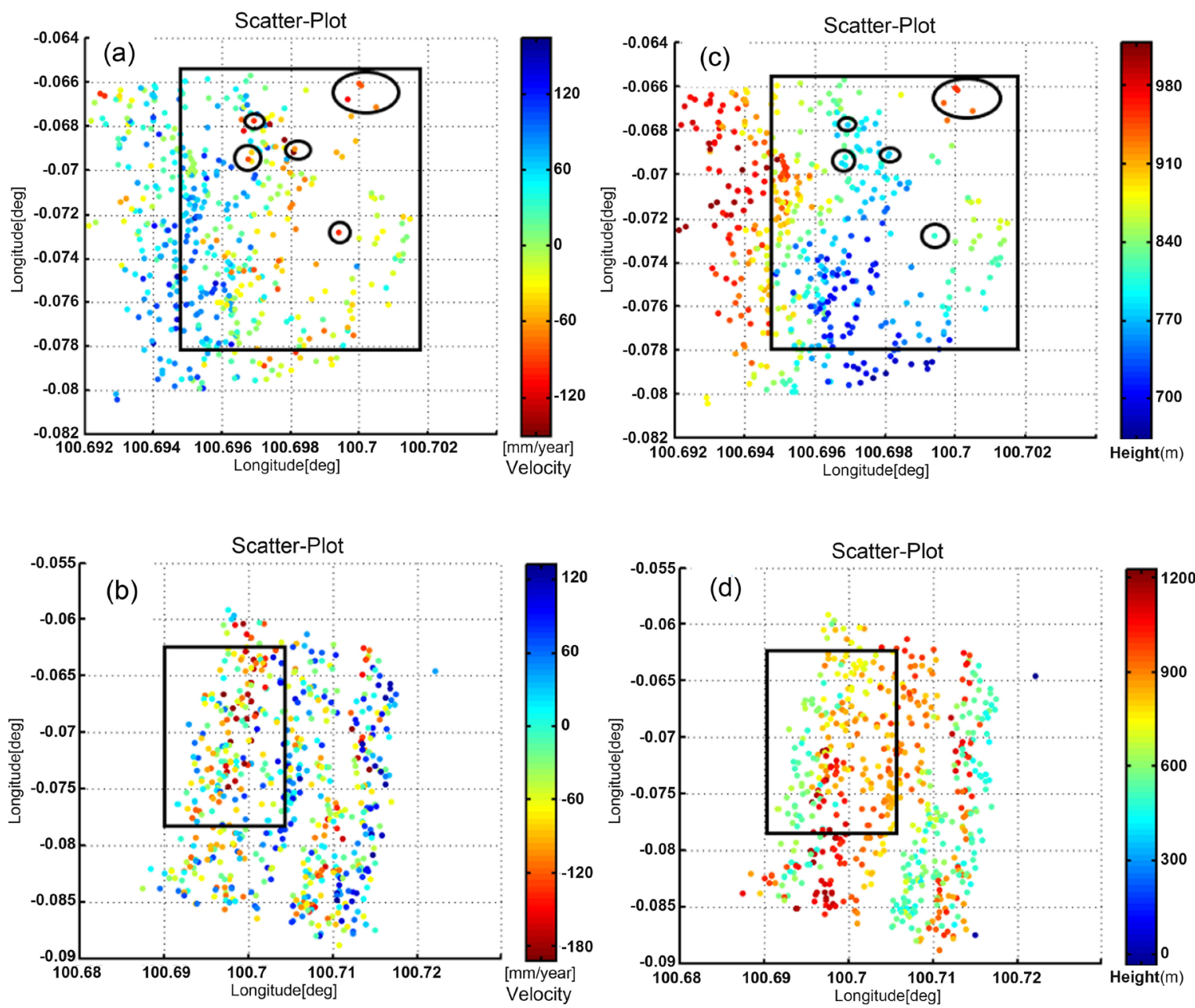

Figure 7. Persistent scatterer plotted in geographic coordinate latitude and longitude. (a) Land deformation velocity which is indicated by color in mm units per year. The maximum velocity is more than $120 \mathrm{~mm} /$ year (red color); (b) Depicted the height of PS also presented in color bar value. The lowest elevation of an area approximately $700 \mathrm{~m}$ and the highest area are more than $980 \mathrm{~m}$ above sea level. The data observed by Sentinel 1A with ascending and descending orbit was supported by 36 and 54 number of scenes from October 2014 to March 2017, respectively. (a) Land deformation velocity ascending orbit; (b) The height of PS for ascending orbit; (c) Land deformation velocity descending orbit; (d) The height of PS for descending orbit.

90 total numbers of scenes. The color of PS point indicated the magnitude of land deformation for both directions with maximum displacements are -512 $\mathrm{mm}$ and $-619 \mathrm{~mm}$ respectively.

Figure 9 presented the land deformation that was modeled using the Inverse Distance Weighted (IDW) interpolation technique based on in contour shape. The interpolation technique is appropriate to illustrate the geological condition of land [8].

\section{Conclusion}

In this paper, we show how Q-PS technique can successfully extract the SAR data of Sentinel-1A (C-band) for detection land deformation in V contour shape 

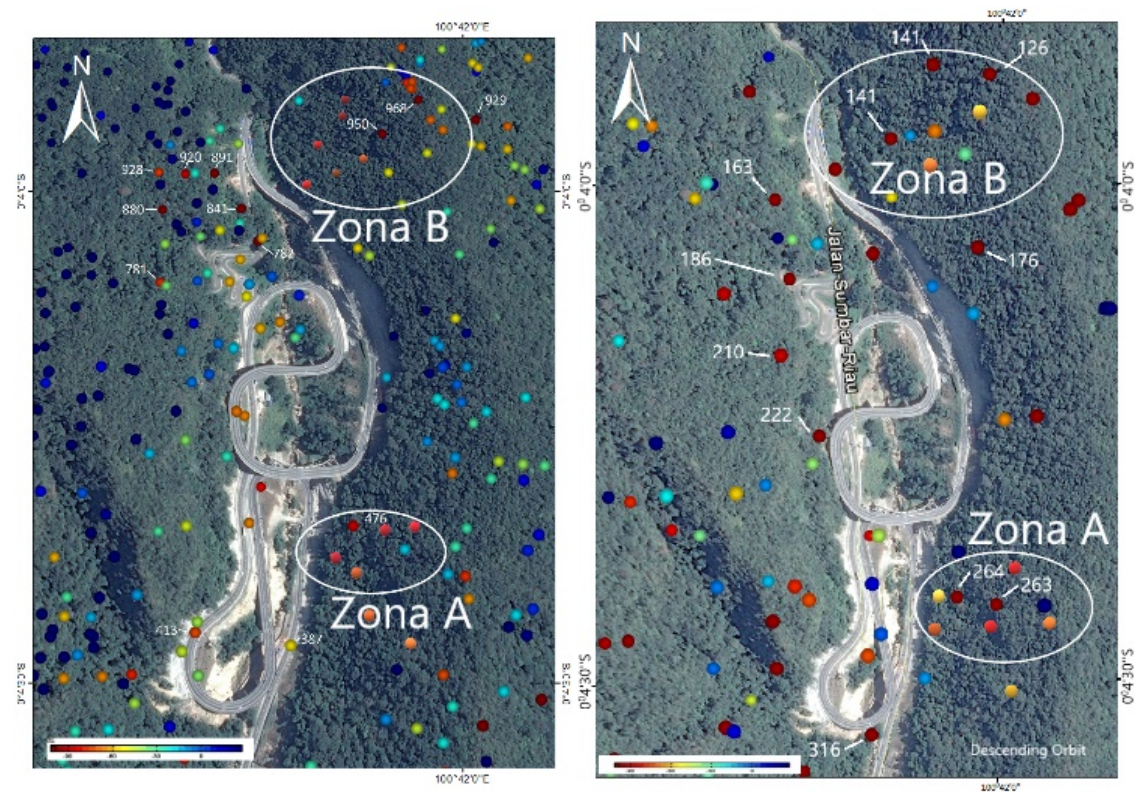

Figure 8. Land deformation area in Kelok Sembilan observed by Sentinel 1A geocoded into an optical layer of Google Earth. (a) Satellite observation with VV polarization in ascending orbit; (b) Satellite observation with VV polarization descending orbit. PS point color indicates the cumulative land deformation on the area. Insert picture below is a color bar of land deformation value in $\mathrm{mm}$.

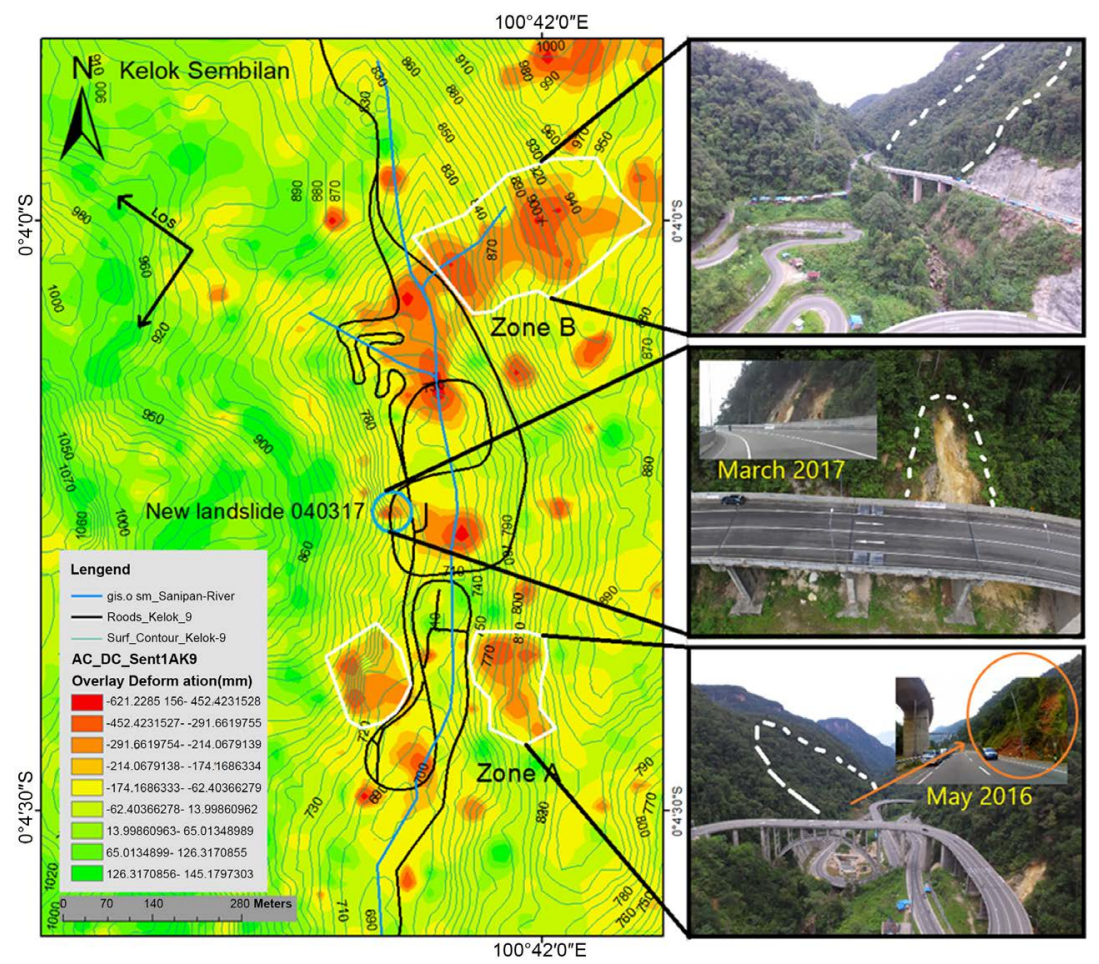

Figure 9. Overlay land deformation area observed from both ascending and descending orbit with co-polarization (VV) and cross-polarization (VH) at Kelok Sembilan area, West Sumatra, Indonesia. White boundaries are zone A and zone B with significant land deformation. The right side is a ground survey, a picture observed by Unmanned Aerial Vehicle (UAV). Inset picture left is deformation displacement in millimeter unit. 
area. The authors have identified and mapped the subsidence and land movement area around Kelok Sembilan Bridge that has the highest potential failure in future. Ninety scenes of Sentinel-1A satellite data over three years ware processed for analysis. Furthermore, by using IDW interpolation technique, the land deformation in Kelok Sembilan region was modeled in contour shape which projected into DEM 12-meter resolution. From the analysis, two (zone A and zone B) of several land deformation areas with large-scale coverage were successfully identified by a cumulative displacement that is more than $500 \mathrm{~mm}$ and velocity $120 \mathrm{~mm} /$ year. Thereupon, the Q-PS processing result analysis was validated and cross cheque with data collected from in situ ground truth observation using drone mapping. Thus, can be concluded that 1 ) the Q-PS technique can be used to land deformation mapping in vegetation area, 2) the Q-PS technique can improve the number of PS point.

\section{Acknowledgements}

The authors would like to thank the Chiba University Excellent International Student Scholarship, KEMENRISTEK DIKTI, Universitas Negeri Padang, ESA Europe, JAXA Japan, SARPROZ, NASA, BNPB, BMKG-SUMBAR

\section{Conflicts of Interest}

The authors declare no conflicts of interest regarding the publication of this paper.

\section{References}

[1] BMKG (2014-2018) Rainfall Intensity. BMKG, Limapuluhkota.

[2] Razi, P., Tetuko, J., Sumantyo, S., Perissin, D. and Munir, A. (2017) Persistent Scattering Interferometry SAR Based Velocity and Acceleration Analysis of Land Deformation: Case Study on Kelok Sembilan Bridge. 2017 11th International Conference on Telecommunication Systems Services and Applications (TSSA), Lombok, 26-27 October 2017, 1-4. https://doi.org/10.1109/TSSA.2017.8272930

[3] Ferretti, A., Prati, C. and Rocca, F. (2001) Permanent Scatters in SAR Interferometry. IEEE Transactions on Geoscience and Remote Sensing, 39, 8-20. https://doi.org/10.1109/36.898661

[4] Perissin, D., Wang, Z., Prati, C. and Rocca, F. (2013) Terrain Monitoring in China via PS-QPS InSAR: Tibet and the Three Gorges Dam. European Space Agency, (Special Publication) ESA SP, 704 SP, 2-6.

[5] Colesanti, C. and Wasowski, J. (2006) Investigating Landslides with Space-Borne Synthetic Aperture Radar (SAR) Interferometry. Engineering Geology, 88, 173-199. https://doi.org/10.1016/j.enggeo.2006.09.013

[6] Sumantyo, J.T.S. et al. (2016) Analysis of Coastal Sedimentation Impact to Jakarta Giant Sea Wall Using PSI ALOS PALSAR. IEEE Geoscience and Remote Sensing Letters, 13, 1472-1476. https://doi.org/10.1109/LGRS.2016.2592940

[7] Hooper, A., Segall, P. and Zebker, H. (2007) Persistent Scatterer Interferometric Synthetic Aperture Radar for Crustal Deformation Analysis, with Application to Volcan Alcedo, Galapagos. Geodesy and Gravity/Tectonophysics, 112, 1-21. 
https://doi.org/10.1029/2006JB004763

[8] Razi, P., et al. (2018) 3D Land Mapping and Land Deformation Monitoring Using Persistent Scatterer Interferometry (PSI) ALOS PALSAR: Validated by Geodetic GPS and UAV. IEEE Access, 6, 12395-12404. https://doi.org/10.1109/ACCESS.2018.2804899

[9] Perissin, D. (2008) Validation of the Submetric Accuracy of Vertical Positioning of PSs in C-Band. IEEE Geoscience and Remote Sensing Letters, 5, 502-506. https://doi.org/10.1109/LGRS.2008.921210

[10] Perissin, D. and Wang, T. (2012) Repeat-Pass SAR Interferometry with Partially Coherent Targets. IEEE Transactions on Geoscience and Remote Sensing, 50, 271-280. https://doi.org/10.1109/TGRS.2011.2160644

[11] ESA (2014) RADAR and SAR Glossary. ESA, Paris.

[12] Duro, J., Sabater, J.R., Albiol, D., Koudogbo, F.N. and Arnaud, A. (2012) Comparative Analyses of Multi-Frequency PSI Ground Deformation Measurements. Proceedings of Fringe 2011, Frascati, 19-23 September 2011, 19-23.

[13] BNPB (2017) Data and Disaster Information of Indonesia. BNPB, Limapuluh Kota.

[14] BNPB (2017) Infografis Bencana Banjir \& Longsor di Kab. Limapuluh Kota, Sumatera Barat. BNPB, Limapuluh Kota.

[15] ESA (2013) Sentinel-1 User Handbook. ESA Publications, Paris.

[16] ESA (2000-2018) Interferometric Wide Swath. ESA, Paris.

[17] Berardino, P., Fornaro, G., Lanari, R., Member, S., Sansosti, E. and Member, S. (2002) A New Algorithm for Surface Deformation Monitoring Based on Small Baseline Differential SAR Interferograms. IEEE Transactions on Geoscience and Remote Sensing, 40, 2375-2383. https://doi.org/10.1109/TGRS.2002.803792

[18] Perissin, D. and Wang, T. (2011) Time-Series InSAR Applications over Urban Areas in China. IEEE Journal of Selected Topics in Applied Earth Observations and Remote Sensing, 4, 92-100. https://doi.org/10.1109/JSTARS.2010.2046883

[19] Perissin, D. (2016) Interferometric SAR Multitemporal Processing: Techniques and Applications. Multitemporal Remote Sensing, Remote Sensing and Digital Image Processing, Springer, Cham, 145-176. https://doi.org/10.1007/978-3-319-47037-5_8

[20] Kampes, B.M. (2006) Radar Interferometry, vol. 12. Springer, Berlin.

[21] Perissin, D. (2016) Multitemporal Remote Sensing, vol. 20. Springer, Berlin. https://doi.org/10.1007/978-3-319-47037-5_8

[22] Perissin, D., Wang, Z. and Wang, T. (2011) The SARPROZ InSAR Tool for Urban Subsidence/Manmade Structure Stability Monitoring in China. 34th International Symposium on Remote Sensing, Sydney, 10-15 April 2011.

[23] Ferretti, A., Prati, C. and Rocca, F. (2000) Analysis of Permanent Scatterers in SAR Interferometry. IEEE Transactions on Geoscience and Remote Sensing, 39, 761-763.

[24] Colesanti, C., Ferretti, A., Locatelli, R., Savio, G. and Colonna, V.V. (2003) Multi-Platform Permanent Scatterers Analysis: First Results. 2nd GRSS/ISPRS Joint Workshop on Remote Sensing and Data Fusion over Urban Areas, Berlin, 22-23 May 2003, 52-56.

[25] Ketelaar, V.B.H.G. (2009) Satellite radar interferometry: Subsidence Monitoring Techniques. Springer, Berlin. https://doi.org/10.1007/978-1-4020-9428-6 